\title{
Dihydropyrimidine Dehydrogenase Inhibitor
}

National Cancer Institute

\section{Source}

National Cancer Institute. Dihydropyrimidine Dehydrogenase Inhibitor. NCI Thesaurus.

Code C2019.

Any substance that inhibits dihydropyrimidine dehydrogenase, a rate limiting enzyme in the degradation of pyrimidines. Inhibition of dihydropyrimidine dehydrogenase increases the biological half-life and efficacy of 5-Fluorouracil (5-FU). 